\title{
Olhar hipertextual: uma perspectiva bakhtiniana da inclusão de imagens na sala de aula
}

\author{
Ângela Álvares Correia Dias \\ Doutora pela Universidade de Londres e mestra pela Universidade de Nova York. \\ Professora adjunta da Faculdade de Educação da Universidade de Brasilia - UnB, \\ atuando na Graduação e no Programa de Pós-Graduação em Tecnologias e Educação. \\ Líder do Grupo de Pesquisa Lattes "Educação Hipertextual". \\ E-mail: angelacdias@bol.com.br
}

Flávia de Souza Fontineles

Graduanda em Pedagogia pela Faculdade de Educação da Universidade de Brasília (UnB).

Pesquisadora de Iniciação Científica (PIBIC/UnB/CNPq) e membro do Grupo de Pesquisa

Lattes "Educação Hipertextual", atuando na linha de pesquisa "Hipertexto na Cultura".

E-mail: fontineles@gmail.com

Karina da Silva Moura

Graduanda em Pedagogia pela Faculdade de Educação da Universidade de Brasília (UnB). Pesquisadora de Iniciaşão Científica (PIBIC/UnB/CNPq) e membro do Grupo de Pesquisa Lattes "Educaşão Hipertextual", atuando na linha de pesquisa "Hipertexto na Cultura".

E-mail: karinasmoura@gmail.com

Mudanças das mais variadas ordens têm emergido no tempo presente, percorrendo quase todas as esferas do nosso cotidiano. São mudanças que vão desde aspectos como as condições naturais do planeta e as demandas para a nossa sobrevivência, até modificações nas produções tecnológicas ou nos paradigmas vigentes e nos sistemas de crenças e valores. Manifestam-se de diferentes maneiras, inclusive por meio das novas formas de comunicação que surgem na sociedade. Machado aponta algumas características comuns às modalidades de comunicação, que emergem no momento histórico que estamos vivenciando:

As imagens e os sons eletrônicos apresentam-se hoje na paisagem urbana de uma forma múltipla, variável, instável, complexa e ocorrem numa variedade infinita de manifestações, invadindo todos os setores da produção cultural e comprometendo todas as especificidades. A eletrônica está presente nas ruas, vitrines, estádios, outdoors, instalações multimídias, ambientes, performances, intervenções urbanas, até mesmo em peças de teatro, salas de concerto, shows musicais e cultos religiosos. [...] A tela eletrônica representa hoje o local de convergência dos saberes e sensibilidades emergentes que perfazem o atual panorama da cultura ${ }^{1}$.

1. MACHADO, A. Prefácio. In: FURTADO, B. Imagens eletrônicas e paisagem urbana: intervenções espaço-temporais no mundo da vida cotidiana. Rio de Janeiro: Relume Dumará, 2002. p. 10. 
2. WALTY, Ivete Lara Camargos; CURY, Maria Zilda Ferreira. Imagens na Educação. Presença Pedagógica, Belo Horizonte: Editora Dimensão, v. 4, n. 19 p. 15-21, jan./fev. 1998.

3. PAULINO, Graça. A cultura como jogo intertextual. In: PAULINO, Graça WALTY, Ivete; CURY, Maria Zilda. Intertextualidades: teoria e prática. Belo Horizonte: Editora Lê, 1995. p. 10.

4. BIAZUS, Maria Cristina V. Ambientes digitais e processos de criação: gerando a produção de sentido. 2001. Tese (doutorado em Informática na Educação), Universidade Federal do Rio Grande do Sul, Porto Alegre, 2001. p. 51.

5. SILVA, Marcos. Sala de aula interativa. 2. ed. Rio de Janeiro: Quartel, 2001. p. 70.
Diante dessa eclosão das novas concepções e maneiras de comunicar presentes em nossa sociedade, reconhece-se a importância de que a educação possibilite a constituição de um cidadão capaz de compreender e enunciar a cultura da qual participa. Assim, é papel da instituição escolar oferecer oportunidades de contato, exploração e produção das mais variadas linguagens, tendo em vista que, como afirmam Walty e Cury:

Dominando o maior número possível de códigos, o cidadão pode interferir ativamente na rede de significação cultural, tanto como receptor quanto como produtor. Na escola ou na sociedade, o processamento de relações que se dá no nível da produção também pode ocorrer no nível da recepção.

A escola pode ser, pois, um espaço privilegiado para recepção crítica dos diferentes códigos e, sobretudo, democraticamente, deve proporcionar acesso mais amplo a eles. Estabelecer relações, inclusive interdisciplinares, é fator fundamental de inserção político-social ${ }^{2}$.

Nesse sentido, muitos têm defendido que a inclusão dos meios digitais no contexto educacional, em especial dos computadores, constitui a principal estratégia para a promoção do referido acesso e o conhecimento da multiplicidade de linguagens e códigos que permeiam as relações sociais.

Paralelo a esse discurso de que os novos recursos tecnológicos - sobretudo o computador conectado à internet - são grandes inovações que trazem inúmeras possibilidades de reinvenção das práticas educacionais, surgem algumas vozes, como a de Graça Paulino, que denuncia: "[...] um país como o nosso convive com a contradição enorme de uma minoria poder usufruir dessa tecnologia mais avançada, enquanto parcelas significativas da população permanecem analfabetas" ${ }^{3}$. A maioria das escolas brasileiras não tem acesso a essas inovações tecnológicas e boa parte delas não tem disponível nem sequer o livro didático.

Além disso, uma análise mais cuidadosa a respeito dos espaços educativos digitais (softwares e sites), quanto à estrutura, ao conteúdo e ao tratamento dado aos textos verbais e imagéticos, demonstra que:

[...] este ambiente, por si só, não garante ao sujeito/educando a condição inventiva se aí não se instaurar um processo dialógico. Tal processo parece estabelecer-se com base em uma proposta pedagógica interativa que inclua situações com desafios favorecendo condições para decisões e escolhas, e estas, na medida em que viabilizarem mudanças internas, gerarem processos de criação ${ }^{4}$.

Assim, mais do que depositar todas as esperanças no meio digital e na informatização, como agentes da implementação de uma educação dialógica, é necessário "aprender com o movimento contemporâneo das técnicas" ${ }^{\text {, trans- }}$ pondo as barreiras do meio em que se dá a comunicação e alçando vôo rumo à construção de ambientes interativos e intertextuais, a partir dos discursos e meios disponíveis.

Como afirma Wandelli, a noção de hipertexto está ainda em processo de construção e sedimentação, contudo, 
[...] dentre tantas incertezas, a primeira afirmativa, quase uma constatação, é a de que o procedimento hipertextual, marcado por características como a escrita em teia, a conexão, a quebra de linearidade, a variedade de recursos gráficos, não surgiu do computador ${ }^{6}$.

Considerando as reflexões produzidas nos trabalhos que realizamos no grupo de pesquisa Educação Hipertextual, podemos afirmar que as características de um hipertexto ultrapassam o meio eletrônico e podem ser implementadas dentro da sala de aula, em atividades presenciais não mediatizadas pelos novos recursos tecnológicos. Muitos trabalhos de nossa autoria (conjunta ou não) e outras produções de colegas integrantes do referido grupo de pesquisa têm identificado características hipertextuais em produções culturais de naturezas diversas (cinema, literatura, hipermídia, livros didáticos). Temos empreendido também estudos que propõem a expansão do conceito de hipertextualidade à práxis pedagógica.

Desse modo, conceitos como interatividade, não-linearidade e heterogeneidade (considerados, habitualmente, como inerentes ao meio eletrônico), são abordados aqui como possibilidades para a educação, mediatizada ou não, partindo de uma concepção de hipertextualidade definida com base nos conceitos bakhtinianos de polifonia, dialogismo e intertextualidade, aliados aos conceitos anteriormente referidos. Essa concepção extrapola a dimensão tecnológica e recai sobre outras produções culturais e, até mesmo, sobre as práticas sociais.

Entende-se por dialogismo o embate de diferentes vozes sociais presentes no contexto sociohistórico. Polifonia, por sua vez, ocorre quando essas vozes ou algumas delas deixam-se escutar, nas interlocuções subjetivas entre o eu e o outro. A intertextualidade representa o cruzamento de textos em que cada palavra tem múltiplas significações, tendo em vista que evocam outras palavras (vozes).

Em princípio, o hipertexto é caracterizado pela não-linearidade predefinida, ou seja, pela multilinearidade. Essa característica multilinear cria um espaço para o exercício da autonomia do leitor, que realiza um processo de construção de sentido por meio das palavras, imagens, sons e outros signos, a partir das escolhas e intervenções que realiza nesse ambiente. O sentido/significado é construído pelo leitor num processo que se inicia pela percepção da produção cultural a ser significada e adentra pelo estabelecimento de relações entre as leituras que porventura já tenha realizado e o que está lendo no momento.

Além disso, o leitor, em processo de significação e elaboração de sentido, acrescenta contribuições (materiais ou subjetivas) à produção observada, realizando intervenções no texto que lhe é apresentado. Assim, no processo de leitura hipertextual de produções culturais, o percurso traçado pelo estudante/leitor se assemelha às considerações de Waizbort a respeito do pensamento de Simmel: "Os caminhos que ele percorre incessantemente são os fios dessa terra, que ele vai tecendo à medida que se movimenta"'.

Nesse sentido, buscamos compreender a inclusão da imagem em atividades pedagógicas a partir de um olhar orientado por alguns princípios entendidos à luz de Bakhtin. Esses princípios trazem a idéia de que ver algo significa estabe-
6. WANDELLI, Raquel. Leituras do hipertexto: viagem ao dicionário Kazar. São Paulo: Imprensa Oficial; Florianópolis: Editora da UFSC, 2003 p. 24.

7. WAIZBORT, Leopoldo (Org.). Dossiê Norbert Elias. São Paulo: Editora Universidade de São Paulo, 1999. 
lecer um diálogo com o que se observa; pois nada tem sua existência afirmada de maneira independente e isolada. Os objetos, as pessoas e os contextos se definem pela interação que formam com os sujeitos que os significam.

Assim, defendemos a constituição de um modo de olhar hipertextual, considerando que, como afirma Goethe, citado por Leite, "olhar apenas para uma coisa não nos diz nada. Cada olhar leva a uma inspeção, cada inspeção a uma reflexão, cada reflexão a uma síntese, e então podemos dizer que, com cada olhar atento, estamos teorizando".

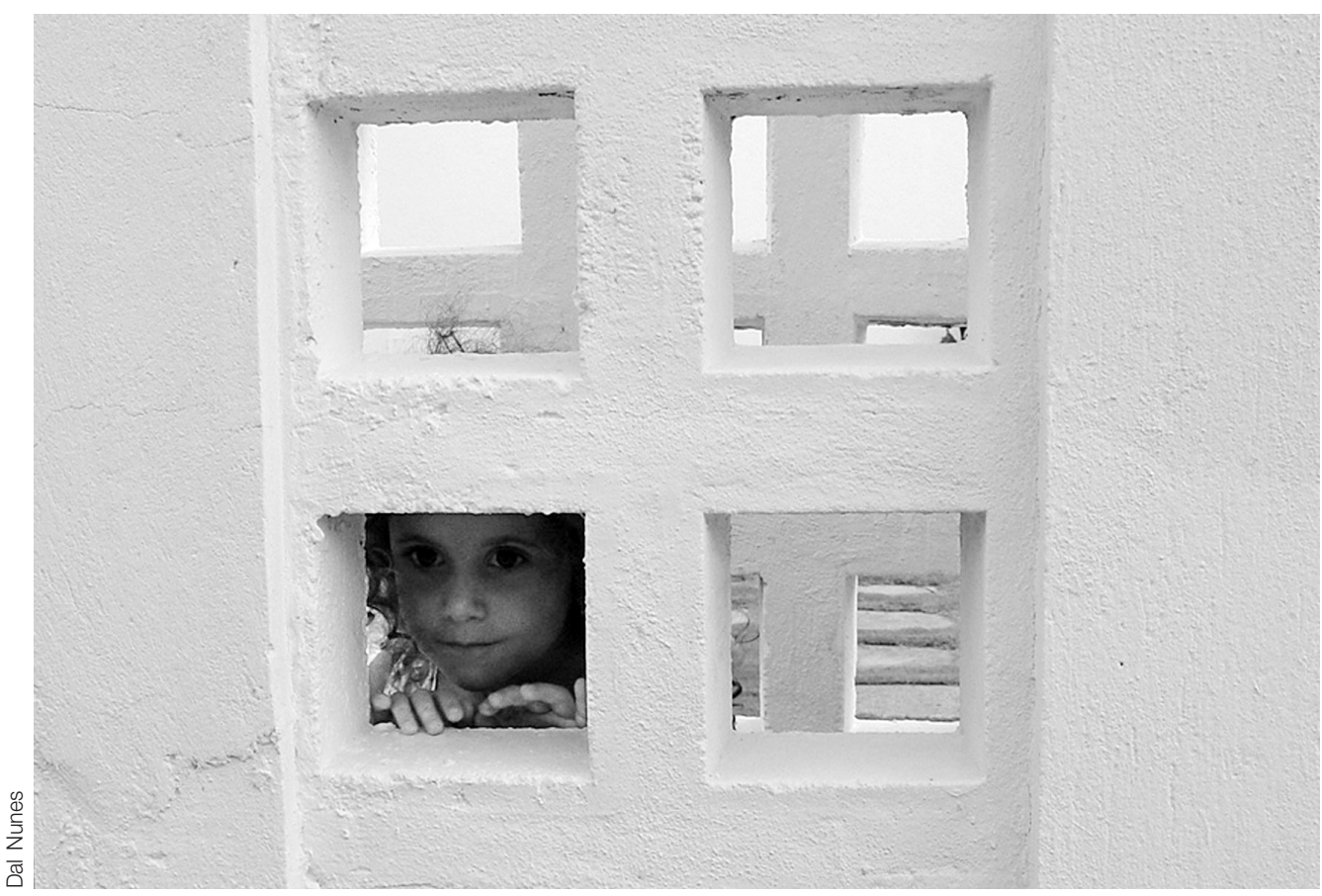

As múltiplas possibilidades do olhar: o início da visão de mundo.

Entendemos que o hipertexto amplia as possibilidades de interatividade e intertextualidade, trazendo mais do que um emaranhado de textos que se interconectam e podem ser lidos na ordem que o leitor escolher. Um ambiente hipertextual é capaz de combinar diversas linguagens e, por apresentar uma estrutura que não hierarquiza os textos, democratiza o espaço da expressão, ao possibilitar que imagens recebam o mesmo tratamento ou tenham o mesmo status que o texto verbal escrito, a despeito da constatação de Leite, de que:

8. LEITE, Miriam L. Moreira. Texto visual e texto verbal. In: FELDMAN-BIANCO, Bela; LEITE, Miriam L. Moreira (Orgs.). Desafios da imagem: fotografia iconografia e vídeo nas ciências sociais. Campinas: Papirus, 1998. p. 40.

9. Ibid., p. 38.
Nos estudos de tradição européia e acadêmica, o texto verbal foi consagrado e tornou-se, mesmo quando desmerecido pela derrocada dos estudos humanos pelos cientificistas, a forma prioritária de expressão ocidental moderna. Os textos visuais, associados com maior freqüência ao contexto artístico e social, ficaram relegados à condição de ilustração dispensável ou superlativa. Muitas vezes são deixados de lado, pela ambigüidade e pelos obstáculos de sua leitura ${ }^{9}$.

Por romper com a estrutura de predefinições de hierarquias axiológicas entre os discursos e os gêneros textuais, a lógica hipertextual subverte uma 
ordem por séculos já estabelecida no mundo ocidental, assumindo que "quer queiramos, quer não, as palavras e as imagens revezam-se, interagem, completam-se e esclarecem-se com uma energia revitalizante. Longe de se excluir, as palavras e as imagens nutrem-se e exaltam-se umas às outras"10.

Por essa razão, acreditamos que o professor necessita utilizar-se de uma espécie de lente, constituída pelas concepções de polifonia e dialogismo (conforme definidas por Bakhtin), para orientar o trabalho educativo, a fim de que os estudantes possam assumir um olhar de caráter hipertextual diante das produções culturais, inclusive das imagens.

Esse olhar hipertextual implica o trabalho pedagógico com imagens, na intenção de instigar diversas interpretações e análises dos diferentes tipos de discursos imagéticos. O que se propõe com isso é explorar conceitos, conteúdos e temas, para que esses sejam geradores de novas formas de construir idéias e percepções, novos modos de olhar, pensar e sentir.

A polifonia, que também se configura num fundamento da hipertextualidade, aparece na ocasião em que concebemos o diálogo como um exercício em que todos os comunicantes têm suas vozes pronunciadas, ouvidas e reconstruídas, num processo que se enriquece intensamente quando essas vozes emergem em um contexto em que a profusão de discursos sociais se faz presente. A inclusão de imagens no trabalho pedagógico, sob a perspectiva da polifonia, possibilita que esses textos sejam compreendidos como expressões da cultura, numa abordagem em que múltiplas interpretações são possíveis e muitos grupos socioculturais podem ser representados por meio de suas produções.

Nessa perspectiva, a imagem é entendida como uma obra, no sentido que Bakhtin atribui ao termo:

A obra, assim como a réplica do diálogo, visa à resposta do outro (dos outros), uma compreensão responsiva ativa. As obras de construção complexa e as obras especializadas pertencentes aos vários gêneros das ciências e das artes, apesar de tudo o que as distingue da réplica do diálogo, são, por sua natureza, unidades de comunicação verbal: são identicamente delimitadas pela alternância dos sujeitos falantes ${ }^{11}$.

Essa definição de imagem pressupõe a interatividade como fundamento de sua própria constituição. A interatividade é um conceito ligado à noção de hipertextualidade, que pode muito bem ser definido a partir da proposição de Gleick, significando que "o ato de jogar o jogo modifica, de certa maneira, as regras"12. A imagem é, então, construída num processo de interação mais ou menos explicitado, que pode apresentar maiores ou menores graus de intervenção direta na materialidade da produção cultural. Ao lermos uma imagem, estamos constituindo um de seus múltiplos significados possíveis, contribuindo para sua existência enquanto cultura, atribuindo-lhe sentido. Lembrando Martins:

Quando começamos a estabelecer relações significativas entre o que nos cerca, também estamos começando a ler. E, avançando, quando passamos a nos reconhecer em face do outro, em nosso estar no mundo, começamos a exercer a capacidade crítica. Isso tudo, muito cedo, bem antes da alfabetização, mas já configurando uma linguagem ${ }^{13}$.
10. JOLY, Martine. Introdução à análise da imagem. Tradução Marina Appenzeller. Campinas: Papirus, 1996. p. 133. (Ofício de Arte e Forma.)

11. BAKHTIN, Mikhail. Estética da criação verbal. São Paulo: Martins Fontes, 1993. p. 298.

12. GLEICK, James. Caos: criação de uma nova ciência. 10. ed. Rio de Janeiro: Campus, 1989. p. 21.

13. MARTINS, Maria Helena (Org.). Outras leituras: literatura, televisão, jornalismo de arte e cultura, linguagem interagente. São Paulo: Editora Senac, 2000. p. 21. 


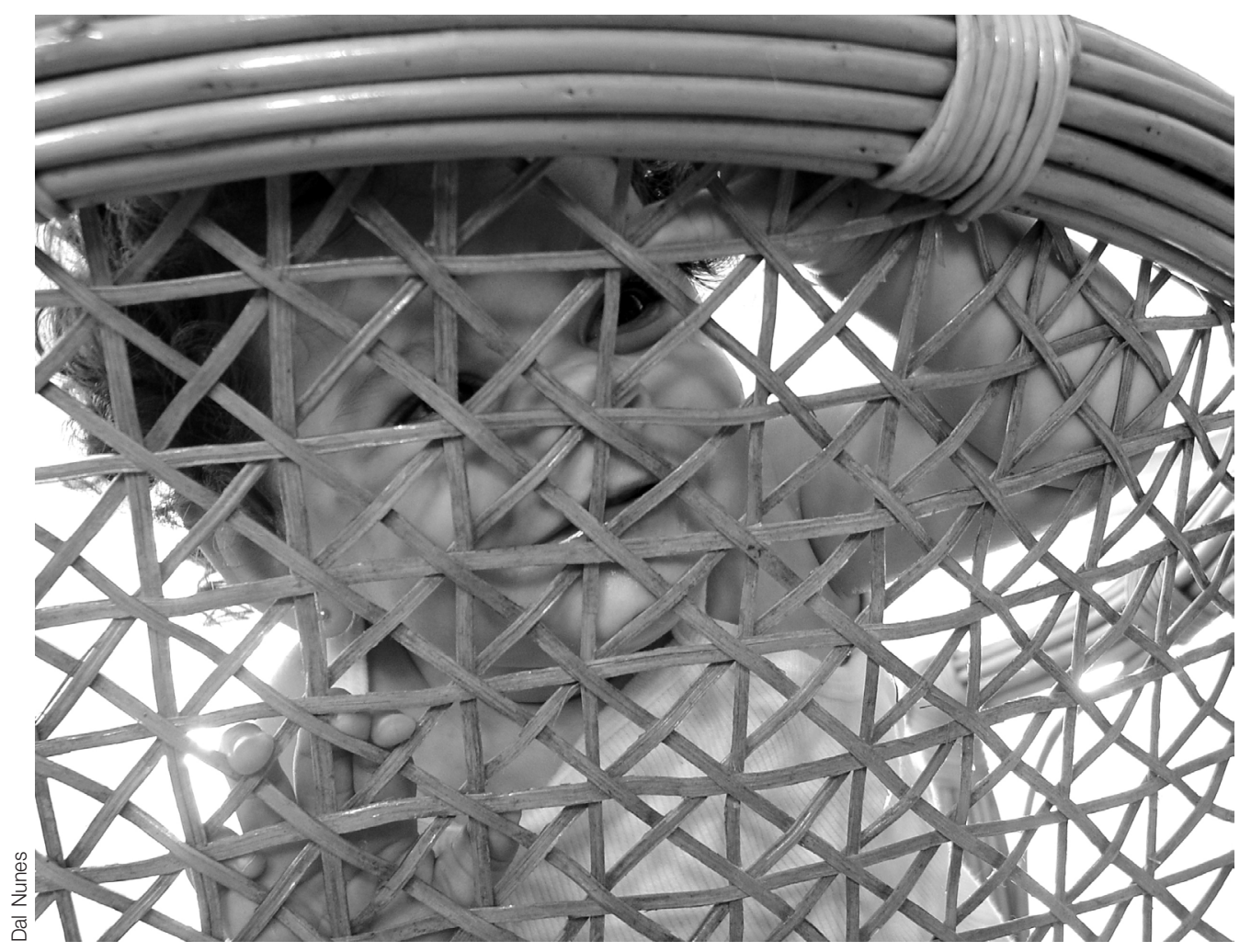

O tecido de significados do mundo tramado pelo olhar: uma busca por vários caminhos.

No caso do trabalho pedagógico, essa interação pode ser estendida ao campo da intervenção na própria materialidade da imagem. Os recursos oferecidos por programas de edição de imagens potencializam esse tipo de intervenção, colocando à disposição do leitor/observador inúmeras ferramentas de reconstrução das imagens. Também recursos menos sofisticados e mais populares como tesoura, cola, tinta e recortes de papel podem ser utilizados para realização de trabalhos pedagógicos de releitura de obras de arte ou de expressão/comunicação através da edição/alteração das imagens apresentadas.

Assim, para a promoção de uma educação que se caracterize pela polifonia, o planejamento das aulas deve ser realizado de modo a possibilitar ações e projetos pedagógicos no campo da multiplicidade, não apenas de diferentes gêneros textuais (filmes, livros, imagens, palavras, jornais e outros), mas também no campo da diversidade de discursos sociais, comunicados por essa variedade de textos.

A concepção hipertextual se alicerça ainda na perspectiva de que o hipertexto oferece possibilidades tangíveis de promoção do diálogo, a partir de atividades interativas e intertextuais, mediatizadas ou não. Assim, o desenvolvimento do olhar hipertextual implica o reconhecimento do outro a partir do exercício do diálogo entre observador e obra (produção cultural) e entre observadores, estabelecendo relações entre a obra e o mundo.

A heterogeneidade, que constitui outro princípio caracterizador do hipertexto, se expressa por meio da inclusão de elementos diferenciados, por vezes conflitantes, num mesmo espaço, exigindo do leitor um desenvolvimento 
apurado do olhar. As imagens têm papel fundamental na promoção da heterogeneidade dos espaços hipertextuais, pois são múltiplas as linguagens que interferem na constituição do discurso imagético, por vezes marginalizado pela suposta supremacia do texto verbal escrito.

Conforme mencionado anteriormente, essas e outras características do hipertexto podem ser identificadas em outros meios, além do virtual, como em algumas produções culturais impressas ou em produções cinematográficas. Como exemplos citamos o livro $O \mathrm{Mez} d a$ Grippe $^{14}$ e os filmes: O Homem que Copiava ${ }^{15}$ e Moulin Rouge - Amor em Vermelho ${ }^{16}$. Wandelli nos chama a atenção para a manifestação de características hipertextuais em uma obra literária:

A rede imensa de histórias interpoladas que entrecortam a narrativa do velho Dom Quixote mostra que os romancistas nunca se limitaram ao modelo aristotélico princípio-meio-fim e buscaram reincidentemente formas mais elásticas para expor suas narrativas fora do jugo da seqüencialidade ${ }^{17}$.

Assim, o professor pode propor a inclusão de produções hipertextuais na escola, mesmo que esta não disponha dos novos recursos tecnológicos, resgatando textos como os imagéticos, que costumam ser subaproveitados ou mesmo banidos do cotidiano escolar. Esses textos tanto podem trazer às salas de aula novas formas de expressão e comunicação como promover experiências de escolha, intervenção e produção de significados.

Contudo, uma grande barreira a ser superada para a realização de um trabalho hipertextual com as imagens e demais produções culturais, a partir dos referenciais bakhtinianos de linguagem, são algumas concepções ainda

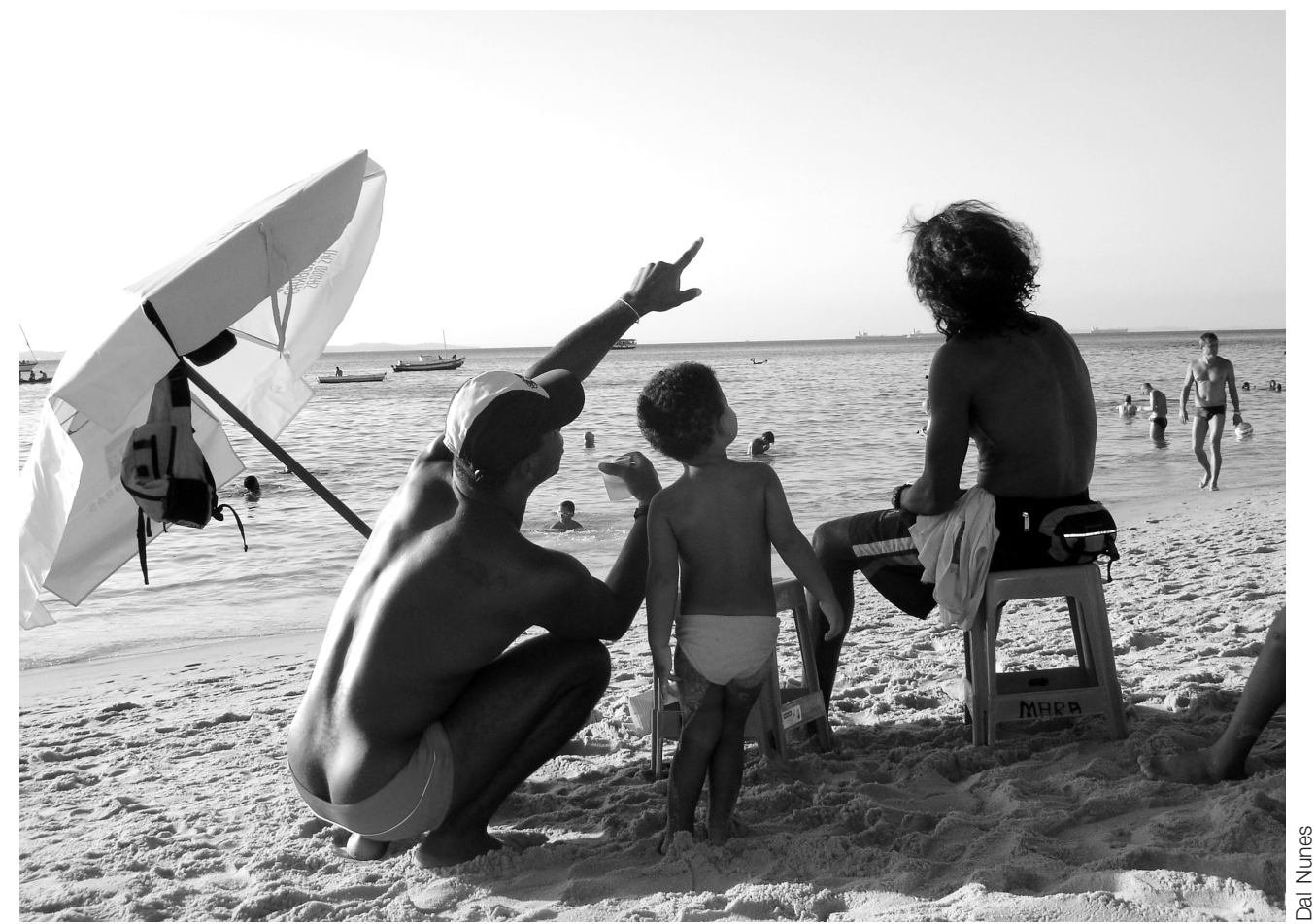

O diálogo com o mundo: um olhar longínquo; visão de futuro.
14. XAVIER, Valêncio. O mez da grippe. São Paulo: Companhia das Letras, 1998. 324 p.

15. O HOMEM que copiava. Direção: Jorge Furtado. Brasil: Casa de Cinema de Porto Alegre, 2002 (130 min.). 1 DVD.

16. MOULIN Rouge - Amor em Vermelho (Moulin Rouge!). Direção: Baz Luhrmann. Austrália/Estados Unidos: Bazmark Films, 2001 (120 min.). 1 DVD.

17. WANDELLI, op. cit., p. 27. 
18. PILLAR, Analice Dutra (Org.). A educação do olhar no ensino das artes. Porto Alegre: Mediação, 1999. p. 12.

19. LARROSA, Jorge. A novela pedagógica e a pedagogização da novela In: __. Pedagogia profana. Belo Horizonte: Autêntica, 1999. p. 12. arraigadas nos currículos dos cursos de formação de professores. Tais cursos têm, historicamente, priorizado a forma de expressão verbal escrita e a maioria nem sequer apresenta a imagem como linguagem socialmente construída, a despeito de ela ser tão presente em nosso cotidiano (em noticiários, outdoors, propagandas, multimídia e outros).

Por essa e por outras lacunas dos currículos de formação, o professor deve assumir-se como descobridor de discursos e maneiras de educar, para que o estudante possa se posicionar como agente reconstrutor da sociedade na qual está inserido. Perceber que, "ao ler uma imagem, o educando entrelaça informações sobre o objeto, características formais, cromáticas, topológicas, suas experiências de vida, conhecimentos e imaginação"18 , é imprescindível para que o professor se torne o educador do olhar, trabalhando com o educando a diversidade de imagens que permeiam suas experiências - dentro e fora do contexto escolar -, reconhecendo e provocando interpretações diversas e considerando que essas interpretações são fruto de um olhar influenciado pelo contexto sociopolítico, ideológico e cultural em que o sujeito se constitui leitor/observador.

Os educadores, ou futuros educadores, nesse processo de assunção do papel de descobridores, não devem se ater à análise das imagens a partir da formalização e abstração (linha, superfície, volume, luz, cor, movimento, direção espacial, ritmo e equilíbrio) representadas e trabalhadas exclusivamente de maneira lógica e formal. É fundamental, a nosso ver, que façam profundas reflexões acerca das imagens, com base em valores sociais, culturais, estéticos e emocionais que essas evocam. Os professores precisam ultrapassar os limites das considerações de ordem racional e formal e empreender leituras mais ousadas, pois "uma prática de leitura como acontecimento da pluralidade e da diferença, como aventura rumo ao desconhecido e como produção infinita de sentido poderia contribuir para esse pensamento aberto sobre a formação humana" 19 .

Nessa perspectiva, a tarefa do educador consiste em provocar os estudantes a submeterem à análise relações que se entrecruzam na superfície da imagem, em um processo no qual esses sujeitos sigam

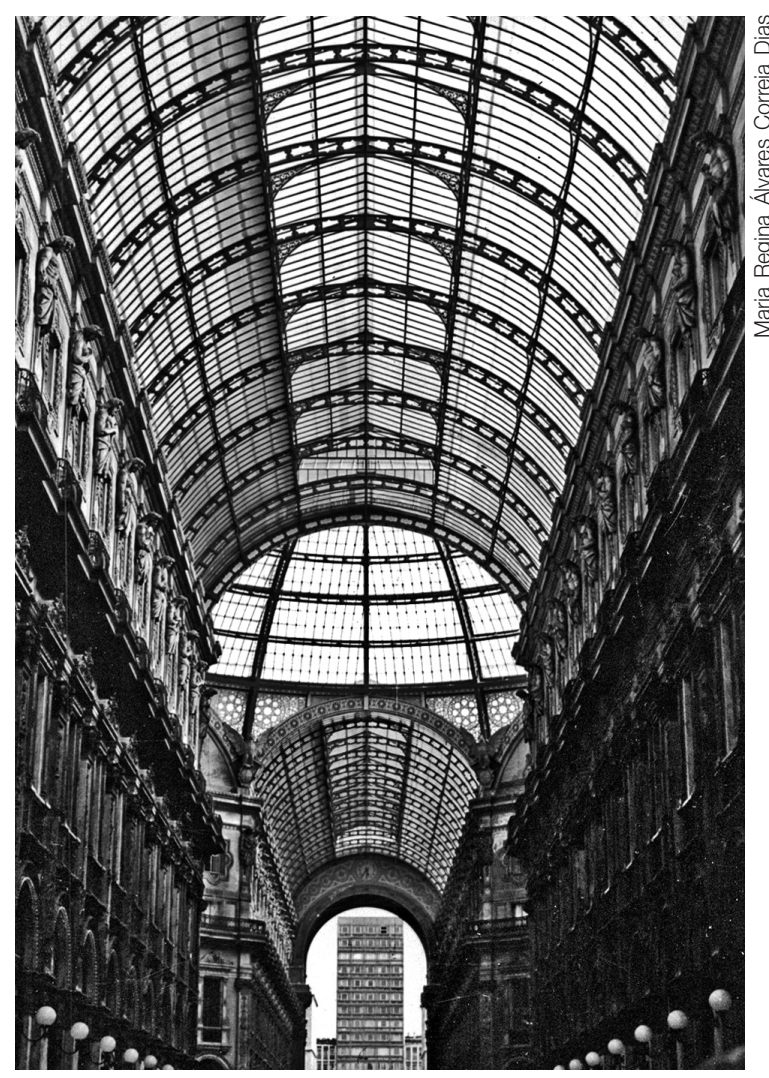

A trama do olhar: um olhar profundo, intenso. 
tecendo e destecendo associações, criando e recriando articulações entre diferentes gêneros de imagens, a fim de construir cadeias de relações e gerar novos conhecimentos.

Nossa proposta é de inclusão de textos imagéticos nas salas de aula, sob a perspectiva bakhtiniana e com o propósito de possibilitar que os educandos e educadores desenvolvam um olhar hipertextual sobre as imagens e sobre o mundo. Em certo sentido, essa proposta é uma filiação às idéias de Paulo Freire, que afirma ser a tarefa do educador: "desafiar o educando com quem se comunica e a quem comunica a produzir sua compreensão do que vem sendo comunicado" ${ }^{20}$; e não se limita à inclusão de imagens no trabalho pedagógico, mas se estende à assunção de uma maneira contemporânea de conceber e experienciar a práxis educativa. Nesse sentido, o que se sugere é a busca por uma educação pautada na hipertextualidade, conceituada a partir do referencial bakhtiniano e permeada por manifestações caracterizadas pela interatividade, não-linearidade, heterogeneidade e intertextualidade (entendidas como versões do dialogismo e da polifonia de Bakhtin). Como proposta para o trabalho com imagens, o olhar hipertextual se insere numa concepção de educação mais dialógica e deve constituir, portanto, um processo criativo de produção de significados.

Resumo: Este artigo apresenta contribuições, geradas a partir das discussões e investigações realizadas pelo Grupo de Pesquisa Lattes/CNPq Educação Hipertextual, para inclusão das imagens nas salas de aula sob uma perspectiva hipertextual. Para tanto, são mostradas algumas características do hipertexto, buscando relativizar o papel das novas tecnologias na promoção de experiências educativas hipertextuais. Apresenta-se, portanto, um conceito amplo de hipertextualidade, construído com base no referencial bakhtiniano, caracterizado pela não-linearidade, heterogeneidade e intertextualidade, entendidas como versões do dialogismo e da polifonia de Bakhtin. $\mathrm{O}$ conceito de imagem também é ampliado, assumindo que imagens são produções culturais que se constituem como textos e, como tais, evocam múltiplas interpretações.

Palavras-chave: educação, tecnologia, hipertexto, imagens, Bakhtin.
Abstract: This article presents contributions that have emerged from the discussions and investigations produced by Hypertextual Education research group concerning to the inclusion of images in classrooms, based on the hypertextual perspective. Some characteristics of hypertext are presented in order to study new technologies role in hypertextual educative experiences. This work extends the hypertextual concept guided by the dialogic and polyphony principles proposed by Mikhail Bakhtin which are characterized by the intertextuality, heterogeneity and non-linearity. The concept of image is also extended, proposing that images are cultural productions constituted as texts, and, so, they may have several interpretations.

Keywords: education, technology, hypertext, images, Bakhtin.
20. FREIRE, Paulo. Pedagogia da autonomia: saberes necessários à prática educativa. 27. ed. São Paulo: Paz e Terra, 1996. p. 38. 